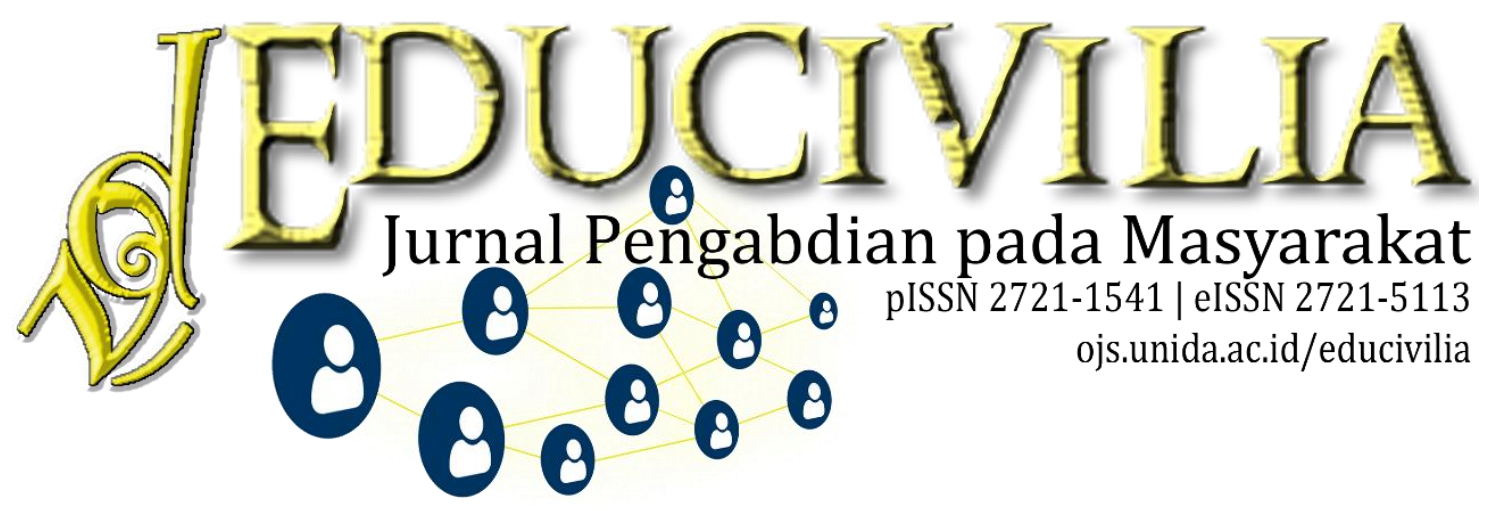

\title{
Pemberdayaan Rumah Literasi Dalam Meningkatkan Semangat Belajar Siswa Di Era Revolusi Industri 4.0
}

\author{
Ariahª, Anita Riyani¹, Chika Siti Sania1 ${ }^{1}$ Muhamad Mu'min¹, Rosameilina F1, \\ Septiana Pancarani ${ }^{1}$, Ulandari ${ }^{1}$ \\ ${ }^{1}$ Universitas Djuanda, Jl. Tol Ciawi No. 1 Kotak Pos 35, Ciawi Bogor 16720 \\ aKorespondensi : Ariah; Email : ariah@unida.ac.id
}

Kilas Artikel

Volume 1 Nomor 2

Juli 2020: 169-175

DOI: $10.30997 /$ ejpm.v1i2.3035

Article History

Submission: 02-07-2020

Revised: 09-07-2020

Accepted: 23-07-2020

Published: 30-07-2020

Kata Kunci:

Revolusi Industri 4.0, Rumah literasi

Keywords:

Industrial Revolution 4.0, Rumah Literasi

Korespondensi:

Ariah

ariah@unida.ac.id

\begin{abstract}
Abstrak
Pengabdian ini dilakukan di Kp. Malingping Desa Warungmenteng, Kecamatan Cijeruk, Kabupaten Bogor. Kegiatan ini bertujuan untuk meningkatkan mutu pendidikn dan memersiapkan anak-anak usia belajar dalam menghadapi tantangan revolusi industri 4.0. Pengabdian ini dilaksanakan dengan membentuk Rumah Literasi. Sebagai pusat sumber belajar, program Rumah Literasi ini kami laksanakan kegiatan-kegiatan edukatif lainnya yang terdiri dari fun learning, bimbingan belajar Malingping, learning motivation, dan semarak anak sholeh. Dari kegiatan pengabdian ini, terdapat peningkatan pengetahuan dan pemahaman masyarakat akan pentingnya pendidikan, tumbuhnya motivasi anak dalam mewujudkan cita-cita di era Revolusi Industri 4.0, serta meningkatnya minat baca anak. Pengabdian program Rumah literasi ini membuktikan bahwa program semacam ini dibutuhkan oleh masyarakat karena kemanfaatannya yang cukup banyak. Oleh karena itu diharapkan kepada para akademisi untuk menyalurkan ilmu dan pengetahuannya kepada masyarakat secara langsung agar terjadi perubahan secara nyata di masyarakat.

Empowerment of Literacy Houses in Improving Student

Learning Enthusiasm in the Industrial Revolution Era 4.0 Abstract

This service is carried out in Kp. Malingping Warungmenteng, Cijeruk, Bogor. This activity aims to improve the quality of education and prepare children of learning age in facing the challenges of the industrial revolution 4.0. This service is carried out by forming a Rumah Literasi. As a learning resource center, this Rumah Literasi program we carry out other educational activities consisting of fun learning, Malingping tutoring, learning motivation, and lively children pious. From this dedication activity, there is an increase in people's knowledge and understanding of the importance of education, the growth of children's motivation in realizing ideals in the era of the Industrial Revolution 4.0, as well as increasing children's reading interest. The service of this Rumah Literasi program proves that this
\end{abstract}


kind of program is needed by the community because of its considerable benefits. Therefore, it is expected that academics will channel their knowledge and knowledge directly to the community so that real changes occur in the community.

\section{PENDAHULUAN}

Revolusi adalah sebuah perubahan besar sosial dan kebudayaan yang berlangsung secara cepat yang menyangkut dasar-dasar atau pokok kehidupan masyarakat. Revolusi industri 4.0 merupakan perubahan kemajuan teknologi baru yang menerapkan dunia digital, dimana terdapat perubahan cara hidup manusia yang serba cepat, yang berdampak kepada kehidupan manusia (Ślusarczyk, 2018).

Revolusi Industri telah mengubah cara kerja manusia dari sistem manual yang kemudian beralih kepada penggunaan mesin atau digital yang dapat memberikan dampak pada semua disiplin ilmu. Dengan perkembangan teknologi yang mengalami perkembangan yang pesat tersebut terdapat banyak terobosan baru dari berbagai disiplin ilmu yang serba digital.

Perkembangan teknologi yang saat ini berada pada revolusi industri 4.0, menuntut manusia untuk dapat bersaing mempertahankan kualitas hidup (Rojko, 2017). Dengan adanya media jaringan internet yang semakin melejit, yang dapat mempengaruhi dan berdampak besar dalam perubahan kehidupan manusia, sehingga harus dipersiapkan sumber daya manusia yang mampu bersaing dengan perkembangan zaman (Kemendikbud, 2017; Muslimin, 2018).

Dalam rangka meningkatkan percepatan pembangunan di Kabupaten Bogor, serta mewujudkan sinergitas dan harmonisasi pembangunan di Wilayah Kabupaten Bogor melalui peningkatan peran lembaga pendidikan secara terintegrasi, maka dilakukan pengabdian di wilayah Desa Warungmenteng, Kecamatan Cijeruk, Kabupaten Bogor.

Meningkatkan mutu pendidikan mempunyai peranan besar dalam kemajuan bangsa (Sya \& Helmanto, 2020). Karena bangsa yang besar adalah bangsa yang memiliki karakter yang kuat dan memiliki kompetensi yang tinggi, yang tumbuh dan berkembang dari pendidikan yang menerapkan nilainilai baik dalam seluruh sendi kehidupan (Lathifah \& Helmanto, 2019). 
Sehingga anak-anak mampu menjadi generasi terbaik penerus bangsa.

Pada era globalisasi ini, siswa perlahan mulai mengenal dengan berbagai informasi berbasis teknologi. Dimana dengan maraknya informasi berbasis teknologi ini dapat dijadikan sebagai salah satu motivasi siswa untuk belajar, sehingga tujuan pendidikan serta citacita siswa dapat diarahkan sesuai dengan cita-cita yang diinginkannya.

Secara umum anak-anak usia sekolah di desa Warungmenteng dapat dikatakan memiliki kemampuan yang standar dalam kualitas pendidikan, hanya perlu bimbingan lebih dari orang tua dalam pembudayaan baca (literasi), dan penambahan fasilitas. Karena anak masih bingung memikirkan apa yang dicita-citakan (tujuan sekolah).

Gerakan Literasi yang diusung Kementerian Pendidikan dan Kebudayaan (Kemendikbud) merupakan salah satu gagasan untuk mempercepat pertumbuhan literasi di Indonesia (Sya, 2020). Hal ini tentunya perlu mendapatkan dukung-an dari berbagai pihak, salah satunya adalah dari keluarga. Gerakan literasi ini menjalar di semua sekolah maupun masyarakat. Oleh karenanya, kami ikut serta dalam mendukung gerakan lite-rasi dengan membuat Rumah Literasi.

Rumah literasi sudah banyak tumbuh di berbagai daerah, begitupun di Desa Warungmenteng ini yang akan kami programkan. Dengan dibuatnya program Rumah Literasi ini diharapkan siswa mampu mempersiapkan dan menghadapi perubahan sosial.

\section{METODE}

Pelaksanaan kegiatan pengabdian ini berlangsung selama 40 hari dari tanggal 1 Agustus - 12 September 2019. Kegiatan ini bertempat di Kontrakan warga di RT/RW 003/004 Desa Warungmenteng Kecamatan Cijeruk Kabupaten Bogor.

Pengabdian ini dilaksanakan dengan membentuk Rumah Literasi. Rumah literasi yang kami lakukan yaitu mendesain tempat seperti ruang belajar umum yang memiliki pojok literasi atau perpustakaan kecil dengan konsep edukasi layaknya suatu kelas yang menjadi pusat sumber belajar anak.

Terdapat beberapa hal yang dapat dijadikan acuan program guna kesuksesan program Rumah Literasi ini, yaitu: 
a. Terdapat Majelis yang dapat dijadikan sebagai Rumah Literasi

b. Pengelola Majelis mampu untuk mengelola dan melanjutkan fungsi Rumah Literasi

Sebagai pusat sumber belajar, program Rumah Literasi melaksanakan kegiatan-kegiatan edukatif lainnya yang terdiri dari 1) fun learning, pelaksanaan pembelajaran yang dikemas dengan metode menyenangkan dan interaktif, dimana fun learning ini dilakukan pada siswa-siswi madrasah. 2) bimbingan belajar Malingping, kegiatan ini yaitu kegiatan belajar tambahan bagi anakanak yang memerlukan bantuan bimbingan belajar dalam materi di sekolah formalnya yang kemudian dibahas di Rumah Literasi. 3) learning motivation, yaitu kegiatan pemberian motivasi belajar siswa yang dilaksa-nakan secara berkala, dan 4) semarak anak sholeh, yaitu kegiatan rutin ta-hunan dalam rangka kompetisi ke-mampuan siswa selama pembelajaran yang dilaksanakan dengan metode perlombaan.

\section{HASIL\& PEMBAHASAN}

\section{Hasil}

Rumah Literasi adalah sebuah wadah/tempat yang didesain menjadi tempat untuk berlangsungnya proses pembelajaran di Kp. Malingping. Rumah literasi ini dibuat bertujuan untuk memfasilitasi kebutuhan siswa dalam rangka menumbuhkan semangat belajar siswa.

Pelaksanaan kegiatan pengabdian ini berlangsung selama 40 hari yang bertempat di Kontrakan warga di RT/RW 003/004 Desa Warungmenteng Kecamatan Cijeruk Kabupaten Bogor. Rumah Literasi yang kami lakukan yaitu mendesain rumah seperti ruang belajar umum yang memiliki pojok literasi atau perpustakaan kecil dengan konsep edukasi layaknya suatu kelas yang menjadi pusat sumber belajar anak.

Sebagai pusat sumber belajar program Rumah Literasi ini kami laksanakan kegiatan-kegiatan edukatif lainnya selain kegiatan menumbuhkan membaca, yang terdiri dari:

Tabel 1. Kegiatan Rumah Literasi

\begin{tabular}{lll}
\hline Program & Keterangan & \multicolumn{1}{c}{ Kegiatan } \\
\hline Fun & Kegiatan & - Pembukaan \\
mengajar di & pembelajaran \\
& Madrasah Di- & (Berdoa, ice \\
niyah Asifa & breaking) \\
& & - Pemberian \\
& materi pembe- \\
& lajaran dengan \\
& metode inter- \\
& & aktif \\
& & Penggunaan \\
& & buku (fasilitas) \\
& di Rumah lite-
\end{tabular}




\begin{tabular}{|c|c|c|}
\hline & & $\begin{array}{l}\text { rasi } \\
\text { - Penutup }\end{array}$ \\
\hline \multirow{13}{*}{$\begin{array}{l}\text { Bimbel } \\
\text { Malingping }\end{array}$} & Kegiatan & - Pembukaan \\
\hline & Bimbingan & pembelajaran \\
\hline & Belajar (tam- & - Kegiatan be- \\
\hline & bahan) bagi & lajar (Menger- \\
\hline & anak-anak & jakan tugas se- \\
\hline & usia sekolah & kolah (formal) \\
\hline & & dan memberi- \\
\hline & & kan penjelasan \\
\hline & & kembali, \\
\hline & & belajar kompu- \\
\hline & & ter, belajar \\
\hline & & membaca dll) \\
\hline & & - Penutup \\
\hline \multirow{7}{*}{$\begin{array}{l}\text { Learning } \\
\text { Motivation }\end{array}$} & Kegiatan & - Pembukaan \\
\hline & penyuluhan & acara \\
\hline & di SDN Leng- & - Penyampaian \\
\hline & is yang bertu- & motivasi \\
\hline & juan untuk & - Games \\
\hline & memotivasi & - Penutup \\
\hline & siswa & \\
\hline \multirow{6}{*}{$\begin{array}{l}\text { Semarak } \\
\text { Anak } \\
\text { Sholeh }\end{array}$} & Kegiatan & - Pembukaan \\
\hline & perlombaan & - Perlombaan \\
\hline & dalam rangka & - Pembagian \\
\hline & memperingati & hadiah \\
\hline & Hari Raya & - Penutup \\
\hline & Idul Adha. & \\
\hline
\end{tabular}

Dari kegiatan tersebut di atas, kegiatan yang dilakukan dengan waktu jangka panjang yaitu fun learning dan Bimbel Malingping, sedangkan kegiatan jangka pendek yang diadakan secara berkala yaitu learning motivation dan semarak anak sholeh.

\section{Pembahasan}

Rumah literasi merupakan salah satu sarana pendukung proses belajar anak-anak yang dijadikan sebagai pusat sumber belajar di Kp. Malingping.

Perkembangan zaman yang menuntut manusia untuk dapat menyesuaikannya dapat dilakukan dengan peningkatan pemahaman siswa akan pentingnya teknologi dan literasi. Pada Rumah literasi ini, kegiatan atau program rumah literasi bertujuan untuk menumbuhkan motivasi belajar siswa salah satunya menyongsong cita-cita di era revolusi industri 4.0 ini.

Pelaksanaan program kegiatan di Rumah literasi ini mendapat partisipasi yang baik, terlihat pada saat berbagai program yang dilaksanakan diikuti oleh banyak siswa, apalagi ketika mereka difasilitasi dengan buku-buku penunjang belajar atau buku bacaan lainnya. Selain itu, antusias mereka juga bertambah ketika proses pembelajaran menggunakan media teknologi.

Adanya rumah literasi dapat dirasakan oleh anak-anak usia sekolah sebagai penunjang belajar mereka. Output yang dihasilkan dari program pengabdian Rumah Literasi yaitu adanya pemahaman dan pengetahuan yang dimiliki oleh anak usia sekolah akan pentingnya perubahan kemajuan 
Revolusi Industri 4.0. Berikut output lain dari kegiatan pengabdian ini yaitu:

a. Semakin banyaknya anak yang termotivasi dalam mempersiapkan dan mewujudkan cita-cita di era Revolusi Industri 4.0

b. Meningkatnya minat anak terhadap budaya baca

Sedangkan output dari masingmasing program pada khususnya yaitu:

Tabel 2. Output Program Rumah Literasi

\begin{tabular}{|c|c|}
\hline Kegiatan & Output \\
\hline Fun Learning & $\begin{array}{l}\text { Penerapan model pembela- } \\
\text { jaran interaktif, yang dapat } \\
\text { menumbuhkan semangat } \\
\text { belajar siswa }\end{array}$ \\
\hline $\begin{array}{l}\text { Bimbel } \\
\text { Malingping }\end{array}$ & $\begin{array}{l}\text { Meningkatnya minat belajar } \\
\text { anak }\end{array}$ \\
\hline $\begin{array}{l}\text { Learning } \\
\text { Motivation }\end{array}$ & $\begin{array}{l}\text { Tumbuhnya kesadaran } \\
\text { siswa dalam menghadapi } \\
\text { tantangan global }\end{array}$ \\
\hline $\begin{array}{l}\text { Semarak Anak } \\
\text { Sholeh }\end{array}$ & $\begin{array}{l}\text { Tumbuhnya minat bakat } \\
\text { anak }\end{array}$ \\
\hline
\end{tabular}

\section{SIMPULAN}

Dari kegiatan pengabdian program Rumah Literasi di Kp Malingping Desa Warungmenteng ini, dapat disimpulkan bahwa program Rumah Literasi dapat meningkatkan pengetahuan dan pemahaman masyarakat akan pentingnya pendidikan, menumbuhkan motivasi anak dalam mewujudkan cita-cita di era Revolusi Industri 4.0, serta meningkatnya minat baca anak.
Dari kegiatan pengabdian kepada masyarakat ini membuktikan bahwa program semacam ini dibutuhkan oleh masyarakat karena kemanfaatannya yang cukup banyak. Oleh karena itu diharapkan kepada para akademisi ataupun mahasiswa untuk menyalurkan ilmu dan pengetahuannya kepada masyarakat secara langsung agar terjadi perubahan secara nyata di masyarakat.

\section{UCAPAN TERIMA KASIH}

Pada pengabdian ini, kami ucapkan terima kasih kepada aparat Desa Warungmenteng yang telah memberikan izin kepada kami untuk melaksanakan pengabdian ini. Tak lupa juga seluruh warga Kp. Malingping Desa Warungmenteng yang telah berkontribusi dalam pelaksanaan program Rumah Literasi. Juga kepada pihak-pihak lain yang telah membantu dalam pelaksanaan pengabdian ini.

\section{DAFTAR PUSTAKA}

Kemendikbud. (2017). Panduan Gerakan

Literasi Nasional.

https://gln.kemdikbud.go.id/glnsite/wp -content/uploads/2017/08/panduangln.pdf $\% 5 \mathrm{C}$

Lathifah, Z. K., \& Helmanto, F. (2019). Orang Tua Sebagai Panutan Islami Untuk Anak. DIDAKTIKA TAUHIDI: Jurnal Pendidikan Guru Sekolah Dasar, 6(2), 131-137. https://doi.org/10.30997/dt.v6i2.2129 Muslimin. (2018). Penumbuhan Budaya Literasi melalui Peningkatan Minat 
Baca Masyarakat Desa. Cakrawala Pendidikan, 37(1), 107-118.

Rojko, A. (2017). Industry 4.0 concept: Background and overview. International Journal of Interactive Mobile Technologies, 11(5), 77-90. https://doi.org/10.3991/ijim.v11i5.707 $\underline{2}$

Ślusarczyk, B. (2018). Industry 4.0 - Are we ready? Polish Journal of Management Studies, 17(1), 232-248. https://doi.org/10.17512/pjms.2018.17. 1.19

Sya, M. F. (2020). Menumbuhkan Minat Baca dan Belajar Anak Melalui Teras Ilmu: Berbasis Pendidikan Karakter Tauhid. Educivilia: Jurnal Pengabdian Pada Masyarakat, 1(1), 29-42. https://doi.org/10.30997/ejpm.v1i1.25 97

Sya, M. F., \& Helmanto, F. (2020). Pemerataan Pembelajaran Muatan Lokal Bahasa Inggris Sekolah Dasar Indonesia. Didaktika Tauhidi: Jurnal Pendidikan Guru Sekolah Dasar, 7(1), 71-81. https://doi.org/10.30997/dt.v7i1.2348 